\title{
Pengembangan Aplikasi Strategi Pencegahan Perilaku Perundungan (Bullying) pada Sekolah Dasar di Kota Jambi
}

\author{
Neni Heryani ${ }^{1}$, Asmuni ${ }^{2}$, Atika F. D. Nst $^{3}$ \\ Jurusan Kebidanan Poltekkes Kemenkes Jambi \\ Email : neniheryanil@gmail.com
}

Submitted $: 12$ /03/2020

Accepted: 26/03/2020

Published: 07/09/2020

\begin{abstract}
Bullying behavior can result in the growth and development of a child, namely trauma and fear so that children do not want to go to school and experience disruption in the learning process. During the period of 2002-2005 there were 30 suicides which happened to victims of abuse at the age range of 6-15 years. Another impact of abuse behavior in childhood is closely related to anti-social behavior in the future after the child grows into adolescents and adults. This type of research and development. This research was conducted in an elementary school environment in the city of Jambi. The population was 48,043 students and 138 research samples. The results of this study the perpetrators of bullying are mostly done by classmates by 77\%. The target of classmates bullying was $73 \%$, the location of the harassment was mostly done in the classroom by $69.6 \%$. The incidence of bullying is low around $45.7 \%$ and the incidence of bullying is high at $54.3 \%$. The conclusion is the incidence of bullying with the grade level of elementary school students does not have a significant relationship. The incidence of bullying with gender does not have a significant relationship. The incidence of bullying with the perpetrator or victim has a significant relationship. There is a significant difference in knowledge in the use of modules and applications with a p-value of 0,000. the use of applications is more effective than the use of modules with a p-value of 0,000
\end{abstract}

Keywords: applications, bullying, prevention

Abstrak
Perilaku bullying dapat berakibat pada tumbuh-kembang seorang anak, yaitu trauma dan ketakutan sehingga anak tidak mau pergi ke sekolah dan mengalami gangguan dalam proses belajar. Selama periode tahun 2002-2005 telah terjadi 30 kasus bunuh diri yang menimpa korban perundungan pada rentang usia 6-15 tahun. Dampak lain dari perilaku perundungan pada masa kanak-kanak erat kaitannya dengan perilaku anti-sosial pada masa mendatang setelah anak tumbuh menjadi remaja dan dewasa. Jenis penelitian pengembangan, Penelitian ini dilakukan di lingkungan sekolah dasar di Kota Jambi. Jumlah populasi 48.043 siswa dan 138 sampel penelitian. Hasil penelitian ini pelaku kejadian bullying banyak dilakukan oleh teman sekelas sebesar 77\%. Sasaran bullying teman sekelas sebesar $73 \%$, lokasi terjadinya perundunga nbanyak dilakukan di ruang kelas sebesar 69.6\% . Kejadian bullying rendah berkisar $45.7 \%$ dan kejadian bullying tinggi sebesar $54.3 \%$. Kesimpulan kejadian bullying dengan tingkatan kelas siswa sekolah dasar tidak memiliki hubungan yang signifikan. Kejadian bullying dengan jenis kelamin tidak memiliki hubungan yang signifikan.Kejadian bullying dengan pelaku atau korban memiliki hubungan yang signifikan.Terdapat perbedaan pengetahuan yang signifikan pada penggunaan modul dan aplikasi dengan $\mathrm{p}$-value 0.000 . penggunaan aplikasi lebih efektif daripada penggunaan modul dengan $\mathrm{p}$ value 0.000 .

Kata kunci: aplikasi, pencegahan, perundungan

\section{PENDAHULUAN}

Di era digital media sosial dan gawai, setiap orang dapat mengakses dan memperoleh dengan mudah segala bentuk informasi yang ada di dunia. Demikian pula anak-anak yang berusia lebih muda, telah pintar menggunakan gadget, dengan hanya menggerakan jari-jemari dan terhubung dengan internet, mereka dapat memperoleh informasi yang diinginkan, ditambah lagi konten-konten negatif seperti perilaku menebar kebencian dan perilaku bully ikut 
terlihat muncul tanpa disengaja, kebanyakan konten muncul tidak sesuai dengan usia.

Tanpa adanya pengawasan dari orang tua dan orang dewasa di sekitarnya, mudah bagi anak-anak usia muda menirunya. Ketidakmampuan mereka untuk memilah dan mengolah informasi inilah yang dapat mempengaruhi perilaku, pemikiran dan sikapnya.

Ada 161 kasus yang tercatat Komisi Perlindungan Anak Indonesia (KPAI). Kasus-kasus tersebut diantaranya; kasus anak korban kasus kekerasan dan bullying mencapai 36 (22,4\%), anak pelaku kekerasan dan bullying mencapat 41 kasus $(25,5 \%)$, anak pelaku tawuran 31 kasus $(19,3 \%)$, anak korban tawuran sebanyak 23 kasus $(14,3 \%)$, dan anak korban kebijakan (pungli), dikeluarkan dari sekolah, tidak boleh ikut ujian, dan putus sekolah) sebanyak 30 kasus $(18,7 \%)$. Menurut pengakuan korban, bully dilakukan secara langsung saat di sekolah dan dilanjutkan di dunia maya yang dikenal istilah "Cyber Bully"

Perilaku bullying dapat berakibat pada tumbuh-kembang seorang anak, khususnya area psikologisnya yaitu trauma dan ketakutan sehingga anak tidak mau pergi ke sekolah dan mengalami gangguan dalam proses belajar. Selain itu, menurut hasil penelitian yang dilakukan yayasan Sejiwa pada tahun 2006 memperlihatkan bahwasanya selama periode tahun 20022005 telah terjadi 30 kasus bunuh diri yang menimpa korban perundungan pada rentang usia 6-15 tahun.

Dampak lain dari perilaku perundungan pada masa kanak-kanak erat kaitannya dengan perilaku anti-sosial pada masa mendatang setelah anak tumbuh menjadi remaja dan dewasa. Tujuan penelitian ini adalah untuk pengembangan aplikasi strategi pencegahan perilaku perundungan (bullying) pada sekolah dasar di kota Jambi

\section{METODE PENELITIAN}

Penelitian ini menggunakan jenis penelitian pengembangan (research and development). Metode penelitian dan pengembangan adalah metode peneltiian yang digunakan untuk menghasilkan produk tertentu, dan menguji keefektifan produk tersebut.

Penelitian jenis ini berbeda dengan penelitian pendidikan lainnya karena tujuannya adalah mengembangkan produk berdasarkan uji coba untuk kemudian direvisi sampai menghasilkan produk yang layak pakai

Populasi penelitian ini adalah siswa Sekolah Dasar di Kota Jambi. jumlah sampel yang digunakan dalam penelitian ini adalah 138 subyek responden. Teknik pengambilan sampel pada penelitian ini menggunakan teknik purposive sampling, teknik ini dilakukan berdasarkan keputusan peneliti yang menurut pendapatnya tampak mewakili populasi. Uji chi-square digunakan untuk meneliti hubungan antara variabel kelas, jenis kelamin, pelaku, dan korban dengan kejadian bullying yang terjadi di sekolah. Menganalisis ketepatan modul dengan perilaku bullying menggunakan aiken's $\mathrm{V}$, sedangkan untuk menguji analisis keefektifan modul dan aplikasi strategi pencegahan perundungan (bullying) dengan menggunakan Uji Wilcoxon.

\section{HASIL DAN PEMBAHASAN \\ Karakteristik Responden}

Tabel 1. Karakteristik Responden berdasarkan Kelas dan Jenis Kelamin pada Siswa Sekolah Dasar di Kota Jambi

\begin{tabular}{|c|c|c|}
\hline Varibel & Frekuensi & Prosentase \\
\hline \multicolumn{3}{|l|}{ Kelas } \\
\hline Kelas 4 & 46 & $33.3 \%$ \\
\hline Kelas 5 & 46 & $33.3 \%$ \\
\hline Kelas 6 & 46 & $33.3 \%$ \\
\hline \multicolumn{3}{|c|}{ Jenis Kelamin } \\
\hline Laki-laki & 105 & $76.1 \%$ \\
\hline Perempuan & 33 & $23.9 \%$ \\
\hline Total & 138 & $100 \%$ \\
\hline
\end{tabular}


melakukan bullying karena perilaku bullying dipersepsikan sebagai suatu mekanisme dalam menjalin interaksi dengan teman sebayanya, berbeda dengan perempuan yang menganggap bullying merupakan tindakan yang membahayakan bagi orang lain sehingga cenderung memilih untuk menghindari perilaku tersebut (Silva, 2013)

Tabel 2 Tingkatan Kejadian Perundungan (Bullying)

\begin{tabular}{|c|c|c|}
\hline $\begin{array}{l}\text { Kejadian } \\
\text { Bullying }\end{array}$ & Frekuensi & Prosentase \\
\hline Rendah & 63 & $45.7 \%$ \\
\hline Tinggi & 75 & $54.3 \%$ \\
\hline Total & 138 & $100 \%$ \\
\hline
\end{tabular}

terjadi antara pelaku dan korban, kejadian bullying rendah berkisar $45.7 \%$ dan kejadian bullying tinggi sebesar $54.3 \%$.

Tabel 3. Distribusi frekuensi tingkat pengetahuan responden sebelum dan setelah diberikan modul pada siswa SD di Kota Jambi.

\begin{tabular}{|c|c|c|}
\hline Tingkat pengetahuan & $\mathrm{F}$ & $\%$ \\
\hline \multicolumn{3}{|l|}{ Pretest } \\
\hline a. Baik & 0 & 0 \\
\hline \multirow{2}{*}{$\begin{array}{l}\text { b. Kurang baik } \\
\text { Total }\end{array}$} & 138 & 100 \\
\hline & 138 & 100 \\
\hline \multicolumn{3}{|l|}{ Post-test } \\
\hline a. Baik & 132 & 95.7 \\
\hline b. Kurang Baik & 6 & 4.3 \\
\hline Total & 138 & 100 \\
\hline
\end{tabular}

Tabel 3 menunjukkan bahwa sebelum di berikan modul strategi pencegahan perundungan, seluruh siswa memiliki tingkat pengetahuan kurang baik (100\%). Setelah dilakukan pemberian modul mengalami peningkatan baik menjadi 95.7 $\%$.
Tabel 4. Perbedaan pengetahuan responden sebelum dan setelah diberikan modul pada siswa SD di Kota Jambi

\begin{tabular}{lcccc}
\hline Pengetahuan & Mean & SD & $p$-value & $\mathrm{N}$ \\
\hline Pretest &, 00 &, 000 &, 000 & 138 \\
Post-test &, 96 &, 205 & &
\end{tabular}

Hasil uji statistik didapatkan $p$-value 0,000 ada perbedaan pengetahuan responden yang signifikan sebelum dan sesudah penggunaan modul strategi pencegahan perundungan (bullying) pada siswa SD di Kota Jambi.

Tabel 5 Distribusi frekuensi tingkat pengetahuan responden sebelum dan setelah diberikan aplikasi pada siswa SD di Kota Jambi

\begin{tabular}{lcc}
\hline \multicolumn{1}{c}{ Tingkat pengetahuan } & F & $\%$ \\
\hline Pretest & & \\
a. Baik & 0 & 0 \\
b. Kurang baik & 138 & 100 \\
Total & 138 & 100
\end{tabular}

\begin{tabular}{|c|c|c|}
\hline Post-test & & \\
\hline $\begin{array}{ll}\text { a. } & \text { Baik } \\
\text { b } & \text { Kurang Baik }\end{array}$ & $\begin{array}{c}138 \\
0\end{array}$ & $\begin{array}{c}100 \\
0\end{array}$ \\
\hline Total & 138 & 100 \\
\hline
\end{tabular}

Sebelum di berikan aplikasi seluruh siswa memiliki tingkat pengetahuan kurang baik $(100 \%)$. Setelah dilakukan pemberian modul mengalami peningkatan menjadi baik yakni $100 \%$.

Tabel 6. Perbedaan pengetahuan responden sebelum dan setelah diberikan aplikasi pada siswa SD di Kota Jambi

\begin{tabular}{ccccc}
\hline Pengetahuan & Mean & SD & p-value & N \\
\hline Pretest &, 00 &, 000 &, 000 & 13 \\
Post-test & 1,00 &, 000 & & 8 \\
\hline Ada & perbedaan & pengetahuan
\end{tabular}

responden yang signifikan sebelum dan sesudah penggunaan aplikasi strategi pencegahan perundungan (bullying) pada siswa SD di Kota Jambi. 
Tabel 7 efektifitas modul dan aplikasi pencegahan perundungan (Bullying) pada siswa Sekolah Dasar di Kota Jambi

\begin{tabular}{lrrrc}
\hline Intervensi & Mean & SD & $\begin{array}{c}p- \\
\text { value }\end{array}$ & $\mathrm{N}$ \\
\hline Modul & 77,68 & 8,737 & 0,000 & 138 \\
Aplikasi & 83,77 & 6,185 & & \\
\hline \multicolumn{4}{c}{ Penggunaan } & \multicolumn{3}{c}{ aplikasi } & strategi
\end{tabular}

pencegahan perundungan (bullying) lebih efektif dari pada penggunaan Modul untuk mencegah perilaku perundungan (bullying) pada siswa Sekolah Dasar di Kota Jambi.

\section{SIMPULAN}

Berdasarkan penelitian ini diperoleh data presentase Kejadian bullying di Sekolah Dasar Kota Jambi tinggi sebesar $54.3 \%$. Terdapat perbedaan pengetahuan responden sebelum dan sesudah diberikan modul strategi pencegahan perundungan (bullying) di Sekolah Dasar di kota Jambi. Terdapat perbedaan pengetahuan responden sebelum dan sesudah menggunakan aplikasi strategi pencegahan perundungan (bullying) di Sekolah Dasar di kota Jambi.Penggunaan aplikasi lebih efektif dibandingkan modul dalam strategi pencegahan perundungan (bullying) bagi siswa Sekolah Dasar di kota Jambi. Pihak sekolah diharapkan dapat memfasilitasi sosialisasi Aplikasi anti Bullying khusus nya kepada siswa sekolah dasar dan dunia pendidikan pada umumnya. Orang tua, guru, serta pemerhati pendidikan anak diharapkan dapat mengakses aplikasi ini

\section{DAFTAR PUSTAKA}

Abdullah, Nandiyah. "Meminimalisasi Bullying di Sekolah," dalam Magistra, Vol. XXV, No. 83, Maret 2013.

American Association of School Administration. (2009). Bullying at School and Online. Eduction.com Holdings, Inc.

Anonym.(2016).

Emotions

Vector.https://www.123rf.com/photo _125387600_stock-vector-boy-with- bad-behavior-bullying-crying-girlcartoon-kid-kicking-his-sister-s-toycubes-children-in-co.

Arya, Lutfi.(2018). Melawan Bullying Menggagas Kurikulum Anti Bullying di Sekolah. Mojokerto: Sepilar

Aryuni, Muthia. (2017) Bullying Prevention Strategies Through The "Care School" Program For Peer Facilitator, Asian Journal of Environment, History and Heritage September 2017, Vol. 1, Issue. 1

Astari, Erza. (2015). Belajar dari Kasus Anggrah Bocah SD yang Tewas karena Ejekan. Diakses melalui https://news.detik.com/berita/belajardari-kasus-anggrah-bocah-sd-yangtewas-karena-ejekan)

Asyhar, Rayandra. (2010).Kreatif Mengembangkan Media Pembelajaran. Jakarta: GP Press

Bussy Little Bugs.(2018) Social and Emotional Learning.Diakses melalui tanggal $11 \quad$ September 2019 https://busylittlebugs.com.au/products lemotions-full-body-flash-cardsautomatic-download

DeLaune, S.C. \& Ladener, P.K. (2002) Fundamental of Nursing : Standards $\&$ Practise. Second Edition. New York: Delmar.

Forrest, Wendy. (1996). Self Concept Differences Between Bullied and Non Bullied Children. Thesis. Faculty of Education, Edth Cowan University.

Hatta, Muhammad. (2017). Tindakan Perundungan (Bullying) dalam Dunia Pendidikan ditinjau berdasarkan hukum pidana Islam. Universitas Malikussaleh Fakultas Hukum. dalam MIQOT vol. XLI No.2 Juli-Desember 2017.

Heat, M.A., \& Sheen, D. (2005).Schoolbased crisis intervention: preparing all personal to assist. New York: The Gilford Press.

Hermalinda, Dewita, Oktariana, E. (2017). Hubungan Karakteristik Remaja 
dengan Perilaku Bullying pada Siswa SMP di Kota Padang. Jurnal Keperawatan Soedirman (The Soedirman Journal of Nursing), Vloume 12, No. 1 Maret 2017.

Hurlock, Elizabeth B. (2011) Psikologi Perkembangan: Suatu Pendekatan Sepanjang Rentnag Kehidupan. Jakarta: Erlangga.

Latifa, Umi. (2017). Aspek Perkembangan pada Anak Sekolah Dasar: Masalah dan Perkembangannya. Journal of Multidisciplinary Studies Vol. 1 No., Juli-Desember 2017. ISSN: 25799703 (P) I ISSN: 2579-9711 (E).

Latifah, Fika. (2012). Hubungan Karakteristik Anak Usia Sekolah dengan kejadian Bullying di Sekolah Dasar X Bogor. Skripsi.Fakultas Keperawatan Universitas Indonesia. Diakses melalui http://lib.ui.ac.id/file?file=digital/203 13561-S43718-

Hubungan\%20karakteristik.pdf

Morcillo, C., Ramos-Olazagasti, M.A., Blanco, C., Sala, R., Canino, G., Bird, H., \& Duarte, Cristiane S. (2015).Socio-cultural context and bullying others in childood.Journal of Child and Family Studies, 24(8), 2241-2249. DOI: $10.1007 / \mathrm{s} 10826-$ 014-0026-1.

Ms Afroz Jan,dkk. (2015).Bullying in Elementary Schools: Its Causes and Effects on Students. Journal of Education and Practice, Vol.6, No.19

Mufrihah, Arina. (2016). Perundungan Reaktif di Sekolah Dasar dan Intervensi Berasis Nuansa Sekolah. Jurnal Psikologi Volume 43, Nomor 2, 2016: 135-153

Notosoedirdjo, M., \& Latipun.(2007). Kesehatan mental; konsep dan penerapan. Malang: UMM Press.

Olweus, D. (1993). Bullying at School.
Oxford: Blackwell Publishing.

Papalia, D.E, Old, S.W., \& Feldman, R.D. (2008).Human Development (Psikologi Perkembangan).Ed. 9.(Terj. A.K. Anwar, (2008)). Jakarta: Kencana.

Putri, Hertika N., Fathra Annis, Riri Novayelinda. (2015). Faktor-faktor yang Berhubungan dengan Perilaku Bullying pada Remaja.JOM Vol. 2 No. 2, Oktober 2015. Diakses melalui https://media.neliti.com/media/public ations/187389-ID-faktorfaktor-yangberhubungan-dengan-per.pdf

Ramdhani, Neila. (2016). Emosi moral dan empati pada pelaku perundungan siber. Jurnal Psikologi, 43(1), 66-80. DOI: $10.22146 / j p s i .12955$.

Robert. (2017). Help Your Kids With Growing Up: A No-Nonsense Guide to Puberty and Adolescence. Dorling Kindersley Limited London.

Santrock, Jhon W. (2011) Perkembangan Anak edisi 7 Jilid 1. (Terjemahan: Sarah Genis B) Jakarta: Erlangga

Santrock, Jhon W. (2011) Perkembangan Anak edisi 7 Jilid 2. (Terjemahan: Sarah Genis B) Jakarta: Erlangga

Syamita, Endah L. (2016). Gambaran Perilaku Bullying pada Remaja di SMP Negeri 11 dan SMP Muhammadiyah 3 Yogyakarta. Naskah Pubilikasi. Program Studi Ilmu Keperawatan fakultas Kedokteran dan Ilmu kesehatan Universitas Muhammadiyah Yogyakarta. Diakses melalui http://repository.umy.ac.id

Teacher Pay Teachers.(2016). Emotion Feeling. Diakses melalui tanggal 11 September 2019 https://www.teacherspayteachers.com /Product/18-Feelings-Posters-withBody-Language-and-FacialExpressions-2858460Winston, 